\title{
BMJ open Accounting for recent trends in the prevalence of diarrhoea in the Democratic Republic of Congo (DRC): results from consecutive cross-sectional surveys
}

\author{
Jacques B O Emina, ${ }^{1,2}$ Ngianga-Bakwin Kandala ${ }^{3,4}$
}

To cite: Emina JBO, Kandala N-B. Accounting for recent trends in the prevalence of diarrhoea in the Democratic Republic of Congo (DRC): results from consecutive cross-sectional surveys. BMJ Open 2012;2:e001930. doi:10.1136/bmjopen-2012001930

\section{- Prepublication history for this paper are available online. To view these files please visit the journal online (http://dx.doi.org/10.1136/ bmjopen-2012-001930).}

Received 4 August 2012 Revised 23 October 2012 Accepted 5 November 2012

This final article is available for use under the terms of the Creative Commons Attribution Non-Commercial 2.0 Licence; see http://bmjopen.bmj.com

For numbered affiliations see end of article.

\section{Correspondence to} Dr Ngianga-Bakwin Kandala; N-B.Kandala@warwick.ac.uk

\section{ABSTRACT}

Objectives: To analyse trends in diarrhoea prevalence by maternal education, access to clean water and improved sanitation, household wealth index; to identify the sources of variation and assess contribution of changes in socioeconomic characteristics in the Democratic Republic of Congo (DRC).

Design: Consecutive cross-sectional surveys. Setting: DRC.

Participants: The databases contain information on 9748 children from the 2001 Multiple Indicators Cluster Survey and 7987 children from the 2007 Demographic and Health Survey.

\section{Interventions: N/A.}

Primary and secondary outcome measures:

Whether the child had diarrhoea 14 days preceding the survey.

Results: The overall prevalence of diarrhoea decreased by 26 percent (from $22.1 \%$ in 2001 to $16.4 \%$ in 2007). Findings from the three complementary statistical methods are consistent and confirm a significant decrease in diarrhoea regardless of socioeconomic characteristics. Changes in behaviour and/or in public health policy seem to be the likely main source of the change. There were no significant changes in diarrhoea prevalence associated with variation of the population structure. It is worth mentioning that the decrease in diarrhoea prevalence is in contrast to the generalised poor living conditions of the population. Therefore, it is difficult to ascertain whether the decline in diarrhoea prevalence was due to real improvement in public-health policy or to data quality issues.

Conclusions: The decline of diarrhoea prevalence in our study need to be further investigated by conducting district-based or provincial-based studies to validate findings from household surveys such as Demographic and Health Surveys and Multiple Indicators Cluster Survey taking into account the current context of the country: ongoing conflict, poor socioeconomic and poor health infrastructure. However, improvement in living conditions such as access to clean water and improved sanitation will contribute to accelerate the reduction of diarrhoea prevalence as well as reduction of child mortality.

\section{ARTICLE SUMMARY}

Article focus

- With about $1 \%$ of the global population, the Democratic Republic of Congo (DRC) has the third highest diarrheal morbidity among under-five children and the fifth highest under-five death rate worldwide. Recent national surveys reports show a decrease in childhood diarrhoea prevalence from $22 \%$ in 2001 to $16 \%$ in 2007.

- Intuitively, the decrease in prevalence of diarrhoea could be explained by: (1) public health improvement nationally or selectively among some specific households and/or (2) increase in the proportion of children living in households with access to water, sanitation and hygiene. We apply appropriate statistical techniques (decomposition analysis and fixed effect regression models) to describe trends in diarrhoea prevalence, identify the actual sources of changes and assess the contribution of selected factors in the observed changes.

- We use data from two consecutive nationally representative household surveys to investigate trends in diarrhoea in the DRC.

Key messages

- Our results provide evidence of a significant decrease in diarrhoea prevalence regardless of socioeconomic characteristics considered.

- The findings indicate that changes in behaviour and/or in public health policy seem to be the likely main source of the observed changes. There were no significant changes in diarrhoea prevalence associated with variation of the population structure.

- However, childhood diarrhoea remains a very important public health issue in the DRC despite the observed decline.

- Moreover, the observed diarrhoea prevalence is in contrast to the poor living conditions and high mortality observed in the same period.

- Therefore, further studies at the district or provincial level are needed to validate our findings. These studies should take into account the current context of the country: ongoing conflict, poor socioeconomic and lack of access to health infrastructures and poor health infrastructure. 


\section{ARTICLE SUMMARY}

Strengths and limitations of this study

- This is the first study of its kind in the DRC that describe trends, identify sources of changes and assess factors contributing to the changes in diarrhoea prevalence among under-five children using two national representative surveys. Furthermore, we used robust statistical techniques to assess changes. The study combines three complementary statistics techniques (trends analysis, decomposition and fixed effect regression models).

- The major limitation of this study is potential data quality issues since data were collected in the conflict and postconflict contexts. Indeed, the significant observed decrease in diarrhoea prevalence in the DRC contrasts with the generalised poor living conditions of the population.

- Another limitation of the study is the way in which diarrhoea was ascertained. It is self-reported and not determined by a medical examination of trained medical staff. Therefore, the respondent may be subjected to recall bias or misinterpretation of symptoms.

\section{INTRODUCTION}

Diarrheal disease is the second leading cause of death among children under five globally. About $22 \%$ of childhood deaths in developing countries are attributable to diarrhoea. ${ }^{1-3}$ It kills more young children than AIDS, malaria and measles combined. ${ }^{3}$

Diarrhoeal diseases are associated with poverty and unhygienic environments. ${ }^{3-5}$ This probably explains the high prevalence of diarrhoea among children whose mothers did not attend school and/or among children living in poorest households particularly in sub-Saharan Africa and South Asia. ${ }^{3}$

With about $1 \%$ of the global population, the Democratic Republic of Congo (DRC) has the third highest diarrhoeal morbidity among under-five children and the fifth highest under-five death rate worldwide. ${ }^{36}$ About $13 \%$ of child deaths are diarrhoea related, approximately 60450 deaths due to diarrhoea in $2010 .^{7}$

However, recent data from national reports show a decrease in childhood diarrhoea prevalence from 2001 to 2010. The prevalence of children with diarrhoea decreased from $22 \%$ in $2001^{8}$ to around $17 \%$ in 2007 and 2010. ${ }^{9} 10$

Intuitively, the decrease in the prevalence of diarrhoea could be explained by: (1) public health improvement globally or selectively among some specific households and/or (2) increase in the proportion of children living in households with access to water, sanitation and hygiene (wealthy household, living in urban areas, whose mothers have secondary education or higher). The question of substantive interest in this context is: how much of the change is actually due to the improvement of public health suggesting the actual decrease in diarrhoea prevalence and how much is due to a compositional change in the population distribution, especially by maternal education, access to clean water and sanitation, household wealth index?

Against this background, this study aims to analyse diarrhoea prevalence by maternal education, access to clean water and improved sanitation and household wealth index. The study will also identify the sources of variation of diarrhoea prevalence in the DRC, and assess the contribution of each factor in the decline of diarrhoea prevalence. To our knowledge, this is the first study of its kind in the DRC as only some descriptive survey reports, ${ }^{8-11}$ and few systematic studies have analysed trends and factors that influence the prevalence of diarrhoea among young children in the DRC. ${ }^{12}$

\section{DATA AND METHODS \\ Data}

This study uses two successive nationally representative household surveys: the 2001 Multiple Indicators Cluster Survey (MICS) and the 2007 DHS. During the 2001 MICS data collection from 21 May to 28 August 2001, three provinces were entirely under the control of the government (Kinshasa, Bas-Congo and Bandundu), four were partially administrated by rebels (Equateur, Katanga, Kasai-Oriental and Kasai Occidental) and four were entirely controlled by rebels (Oriental, Nord Kivu, Sud Kivu and Maniema). Though the 2007 DHS was carried out after the 2006 elections (2 February-30 April 2007 for Kinshasa, and from 10 May-31 August 2007 for the remaining provinces), some villages and municipalities in the Eastern provinces of Nord-Kivu, Sud-Kivu and Oriental were under armed conflict.

The two datasets have comparable information on household characteristics and child diarrhoea at the time of the survey. The sample design and questionnaire are described elsewhere. ${ }^{8} 9$ Consequently, the two surveys offer the opportunity of analysing change in diarrhoea prevalence in the DRC. In total, the 2001 MICS database includes information about 8600 households and 9748 under-five children, whereas the 2007 DHS database had information about 8886 households and 7987 children.

For each child under the age of five, the survey respondent in the household was asked whether the child has had diarrhoea in the past 2 weeks prior to the surveys as indicated in the Box 1 and in French language.

\section{Box 1 Question on diarrhoea among under-five children}

1. 2001 MICS: ((Nom de l'enfant) a-t-il/elle eu la diarrhée au cours des 2 dernières semaines, c'est-à-dire, depuis ( jour de la semaine) de l'avant dernière semaine ? in French). Has (name of the child) had diarrhoea in the last 2 weeks, that is, since (day of the week) of the week before last.

2. 2007 DHS:((Nom de l'enfant) a eu la diarrhée au cours des deux dernières semaines? In French) 'Has (name of the child) had diarrhoea in the past 2 weeks? 
Therefore, diarrhoea is determined not by medical examination but it is self-reported by the mother or caretaker with symptoms of three or more loose or watery stools per day or blood in stool.

\section{Variables}

Exposure to diarrhoea-causing agents is frequently related to the use of contaminated water and to unhygienic practices in food preparation and disposal of excreta. Poor sanitation, lack of access to clean water and inadequate personal hygiene are responsible for an estimated $90 \%$ of childhood diarrhoea. ${ }^{3-5} 13$

Exposure variables for this study include maternal education, access to clean water and sanitation and household wealth index. A large body of empirical work has shown association between these variables and the prevalence of diarrhoea among under-five children. ${ }^{3}$ 12-18

We define clean water or drinking water as water of sufficiently high quality that can be consumed or used with low risk of immediate or long-term harm. It is drawn from an improved drinking water source protected from outside contamination, in particular from contamination with faecal matter including piped water (into residence or plot), public tap, tube well, protected dug wells and protected springs. ${ }^{19} 20$ An improved sanitation facility is defined as one that is likely to hygienically separate human excreta from human contact: public sewer, septic tank, pour-flush latrine, pit latrine with slab, ventilated improved pit and ecological sanitation. ${ }^{19} 20$ The MICS and DHS surveys collecting these variables use the same definition and categorisation. ${ }^{21} 22$

In this study, household wealth index is measured with an asset index and wealth quintile constructed using the statistical Procedure Principal Component Analysis developed by Filmer and Pritchett. ${ }^{23}$ The index measures economic status based on housing characteristics, household assets and possession of household consumer durables as well as access to clean water and improved sanitation. The 2001 MICS and 2007 DHS have collected these data. Using rank methods, households are classified by quintile of wealth.

\section{Statistical methods}

This study uses three complementary methods: trends analysis, decomposition and longitudinal multivariate models (fixed effect regression models). The Stata, 'nptrend' command performs a non-parametric test of trend for the ranks across ordered groups. The test is an extension of the Wilcoxon rank-sum test. ${ }^{24}$ The test provides $\mathrm{Z}$ statistics and $\mathrm{p}$ value showing whether the change is statistically significant or not.

The decomposition approach divides the trends in child's diarrhoea prevalence into change in population structure and change in health behaviour and/or public health over the study period. ${ }^{25} 26$ This method assumes that the historical change in child diarrhoea prevalence depends on: (1) trends in distribution of under-five children by access to clean water and improved sanitation facility, household wealth index and maternal education over time (composition effect); (2) actual change in diarrhoea prevalence due to change in health behaviour or improvement in public health (the basic effect) that is the regression intercept when $\mathrm{x}=0(\alpha) ;(3)$ variation of diarrhoea prevalence by exposure variables $(\beta)$, and the residual effect of other variables not considered as $\mathrm{e}$ error term $(\mu)$. This change can be presented as follows:

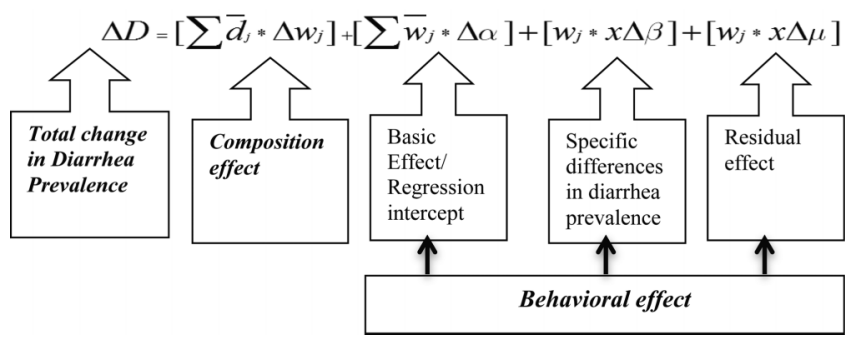

The decomposition analyses are performed at an aggregated/cluster level (the national level by maternal education and household living conditions).

Finally, we use a fixed-effect regression model to explore the relationship between women education and modern contraceptive use within the country. The equation for the fixed effects model is displayed below:

$$
\mathrm{Y}_{\mathrm{it}}=\beta_{1} \mathrm{X}_{\mathrm{it}}+\alpha_{\mathrm{i}}+\mu \mathrm{i}_{\mathrm{t}}
$$

where

- $\alpha_{\mathrm{i}}(\mathrm{i}=1 \ldots \mathrm{n})$ is the unknown intercept for each entity (n entity-specific intercepts);

- $\mathrm{Y}_{\mathrm{it}}$ is the dependent variable (diarrhoea prevalence) where $\mathrm{i}=$ children and $\mathrm{t}=$ time;

- $\mathrm{X}_{\mathrm{it}}$ represents the independent variable (child' age, province of residence, household living conditions);

- $\beta_{1}$ is the coefficient for the independent variable (maternal education, access to clean water and sanitation, and household wealth index);

- $\mu_{1}$ is the error term.

To perform the fixed effect models, we constructed three independent panel datasets (maternal education, access to clean water and improved sanitation and household wealth index). Each dataset has multiple observations about each category of the independent variable considered as individual (number of surveys, two in our case). Therefore, the maternal education database contains six observations, while numbers of observations for the access to clean water and improved sanitation and the household wealth index database are, respectively, estimated at 8 and 10 observations; each database contains the following information proportion of under-five children, year of survey and diarrhoea prevalence.

\section{RESULTS}

\section{Sample description}

Table 1 presents the distribution of under-five children by selected background characteristics in each sample. 
Table 1 Background characteristics of under-five children in DRC (2001 and 2007)

\begin{tabular}{|c|c|c|c|c|}
\hline & \multicolumn{2}{|c|}{2001 MICS } & \multicolumn{2}{|c|}{2007 DHS } \\
\hline & $\begin{array}{l}\text { Per } \\
\text { cent }\end{array}$ & Number & $\begin{array}{l}\text { Per } \\
\text { cent }\end{array}$ & Number \\
\hline \multicolumn{5}{|l|}{ Child sex } \\
\hline Male & 49.8 & 4855 & 49.5 & 3956 \\
\hline Female & 50.2 & 4893 & 50.5 & 4031 \\
\hline \multicolumn{5}{|c|}{ Child age in months } \\
\hline $0-5$ & 11.1 & 1070 & 11.5 & 919 \\
\hline $6-11$ & 11.3 & 1090 & 10.8 & 865 \\
\hline $12-23$ & 22.3 & 2162 & 20.4 & 1632 \\
\hline 24-35 & 19.2 & 1864 & 19.8 & 1582 \\
\hline $36-47$ & 17.6 & 1709 & 19.0 & 1519 \\
\hline $48-59$ & 18.5 & 1792 & 18.4 & 1470 \\
\hline \multicolumn{5}{|c|}{ Access to clean water and sanitation } \\
\hline None & 11.8 & 1153 & 13.0 & 1039 \\
\hline Water only & 6.7 & 654 & 1.4 & 111 \\
\hline Toilet only & 41.1 & 4008 & 57.6 & 4604 \\
\hline Water and toilet & 40.4 & 3933 & 28.0 & 2233 \\
\hline \multicolumn{5}{|l|}{ Place of residence } \\
\hline Urban & 35.4 & 3446 & 41.1 & 3282 \\
\hline Rural & 64.6 & 6302 & 58.9 & 4705 \\
\hline \multicolumn{5}{|c|}{ Province of residence } \\
\hline Kinshasa & 13.9 & 1352 & 10.7 & 852 \\
\hline Bas-Congo & 5.3 & 515 & 7.4 & 590 \\
\hline Bandundu & 11.9 & 1162 & 9.2 & 734 \\
\hline Equateur & 11.4 & 1107 & 9.9 & 789 \\
\hline Orientale & 10.0 & 974 & 7.1 & 567 \\
\hline Nord-Kivu & 7.3 & 708 & 8.7 & 691 \\
\hline Maniema & 6.1 & 593 & 9.2 & 736 \\
\hline Sud-Kivu & 2.6 & 253 & 8.9 & 710 \\
\hline Katanga & 11.3 & 1100 & 9.6 & 766 \\
\hline Kasai Oriental & 10.9 & 1058 & 10.3 & 826 \\
\hline Kasai & 9.5 & 926 & 9.1 & 726 \\
\hline \multicolumn{5}{|l|}{ Occidental } \\
\hline \multicolumn{5}{|l|}{ Maternal education } \\
\hline None & 27.5 & 2680 & 23.9 & 1909 \\
\hline Primary & 41.2 & 4015 & 42.2 & 3369 \\
\hline $\begin{array}{l}\text { Secondary and } \\
\text { high }\end{array}$ & 31.3 & 3053 & 33.9 & 2709 \\
\hline \multicolumn{5}{|c|}{ Household Wealth Index } \\
\hline Poorest & 20.0 & 1953 & 22.0 & 1759 \\
\hline Second & 19.5 & 1903 & 20.2 & 1609 \\
\hline Middle & 19.6 & 1911 & 19.5 & 1555 \\
\hline Fourth & 19.3 & 1877 & 20.9 & 1669 \\
\hline Richest & 21.6 & 2104 & 17.5 & 1395 \\
\hline Total & 100.0 & 9748 & 100.0 & 7987 \\
\hline \multicolumn{5}{|c|}{$\begin{array}{l}\text { Source: 2001DRC-MICS; } 2007 \text { DRC-DHS. } \\
\text { Note: Sometime N<total due to missing values. } \\
\text { DHS, Demographic and Health Surveys; DRC, Democratic } \\
\text { Republic of Congo; MICS, multiple indicators cluster survey. }\end{array}$} \\
\hline
\end{tabular}

The database contains information on 9748 children from the 2001 MICS and 7987 children from the 2007 DHS. The characteristics of under-five children shown in table 1 reveal differences in structure across surveys except if one considers child' age and sex. For instance, the proportion of children living in households with access to clean water and to toilets decreased from $40 \%$ in 2001 to $28 \%$ in 2007. Moreover, the proportion of under-five children by province of residence varies across surveys. In 2001, the largest proportion of children sample was from Kinshasa (14\%) and in 2007 a large proportion of children came from Kasai Oriental and Kinshasa.

Trends in diarrhoea prevalence in the DRC

Table 2 describes trends in diarrhoea prevalence in the DRC from 2001 to 2007.

There is a decrease in the prevalence of diarrhoea. Overall, the prevalence of diarrhoea in the DRC declined by $26 \%(\mathrm{Z}=-9.7, \mathrm{p}<0.000)$ from $22 \%$ in 2001 to $16 \%$ in 2007 . However, this decrease in diarrhoea prevalence is not statistically significant among children who reside in households with water alone without toilet $(\mathrm{Z}=-1.46, \mathrm{p}=0.143)$.

\section{Decomposition of diarrhoea prevalence changes} in the DRC

We decompose changes in diarrhoea prevalence by maternal education, housing living conditions and household wealth index. This may contribute to the understanding on how the observed changes relate to variations in the survey population structure or to changes in public health and/or changes in behaviour. Table 3 presents results of the decomposition analysis.

Table 2 Prevalence of diarrhoea among under-five children in DRC, 1995-2007

\begin{tabular}{|c|c|c|c|c|c|}
\hline \multirow{3}{*}{$\begin{array}{l}\text { Background } \\
\text { variables }\end{array}$} & \multicolumn{2}{|l|}{ Year } & \multirow{2}{*}{$\begin{array}{l}\text { Variation (\%) } \\
2001-2007\end{array}$} & \multicolumn{2}{|c|}{ nptrend test } \\
\hline & 2001 & 2007 & & \multirow[t]{2}{*}{$\mathbf{Z}$} & \multirow{2}{*}{$\frac{p \text { Value }}{0.000}$} \\
\hline & 1 & 2 & 3 & & \\
\hline \multicolumn{6}{|c|}{ Maternal education } \\
\hline None & 22.5 & 15.8 & -30.0 & -4.24 & 0.000 \\
\hline Primary & 22.9 & 18.9 & -17.4 & -5.29 & 0.000 \\
\hline $\begin{array}{l}\text { Secondary } \\
\text { and+ }\end{array}$ & 20.8 & 13.9 & -33.4 & -7.50 & 0.000 \\
\hline \multicolumn{6}{|c|}{ Water and sanitation } \\
\hline None & 25.8 & 18.2 & -29.3 & -4.14 & 0.000 \\
\hline $\begin{array}{l}\text { Water } \\
\text { alone }\end{array}$ & 23.4 & 19.5 & -16.8 & -1.46 & 0.143 \\
\hline $\begin{array}{l}\text { Toilet } \\
\text { alone }\end{array}$ & 21.4 & 16.2 & -24.2 & -5.96 & 0.000 \\
\hline $\begin{array}{l}\text { Water and } \\
\text { toilet }\end{array}$ & 21.6 & 15.9 & -26.7 & -6.46 & 0.000 \\
\hline \multicolumn{6}{|c|}{ Household wealth index } \\
\hline Poorest & 20.8 & 17.0 & -18.2 & -2.12 & 0.030 \\
\hline Second & 24.9 & 15.7 & -37.0 & -6.08 & 0.000 \\
\hline Middle & 23.4 & 16.2 & -30.6 & -5.65 & 0.000 \\
\hline Fourth & 23.3 & 18.3 & -21.5 & -4.82 & 0.000 \\
\hline Richest & 18.7 & 14.4 & -22.8 & -3.99 & 0.000 \\
\hline Total (DRC) & 22.1 & 16.4 & -25.8 & -9.74 & 0.000 \\
\hline \multicolumn{6}{|c|}{$\begin{array}{l}\text { Source: 2001DRC-MICS; } 2007 \text { DRC-DHS. } \\
\text { Variation (3)=((Prevalence in 2007/Prevalence in 2001)-(1)) } \times 100 \text {. } \\
\text { DHS, Demographic and Health Surveys; DRC, Democratic } \\
\text { Republic of Congo; MICS, multiple indicators cluster survey. }\end{array}$} \\
\hline
\end{tabular}


Table 3 Decomposition of trends in diarrhoea prevalence in the DRC 2001-2007

\begin{tabular}{|c|c|c|c|c|c|c|}
\hline & \multicolumn{4}{|c|}{ Behavioural effect } & \multirow[b]{2}{*}{$\begin{array}{l}\text { Effect of composition } \\
\text { A }\end{array}$} & \multirow[b]{2}{*}{$\begin{array}{l}\text { Contribution } \\
\text { C }\end{array}$} \\
\hline & $\begin{array}{l}\text { Base } \\
\text { B1 }\end{array}$ & $\begin{array}{l}\text { Differentiation } \\
\text { B2 }\end{array}$ & $\begin{array}{l}\text { Error } \\
\text { B3 }\end{array}$ & $\begin{array}{l}\text { Total } \\
\text { B }\end{array}$ & & \\
\hline \multicolumn{7}{|l|}{ Maternal education } \\
\hline None & -1.422 & 0.000 & -0.243 & -1.665 & -0.764 & $43.4 \%$ \\
\hline Primary & -2.317 & -0.079 & 0.792 & -1.604 & 0.149 & $26.0 \%$ \\
\hline Secondary and+ & -1.837 & -0.125 & -0.314 & -2.277 & 0.566 & $30.6 \%$ \\
\hline Overall & $99.7 \%$ & $3.6 \%$ & $-4.2 \%$ & $99.1 \%$ & $0.9 \%$ & 100.0 \\
\hline \multicolumn{7}{|l|}{ Water and sanitation } \\
\hline None & -0.732 & 0.000 & -0.349 & -1.081 & -0.447 & $27.3 \%$ \\
\hline Water alone & -0.108 & 0.007 & 0.087 & -0.014 & -0.526 & $9.7 \%$ \\
\hline Toilet alone & -3.201 & 0.438 & -0.580 & -3.343 & 0.945 & $42.8 \%$ \\
\hline Water and toilet & -1.149 & 0.236 & -0.169 & -1.082 & -0.050 & $20.2 \%$ \\
\hline Overall & $92.7 \%$ & $-12.2 \%$ & $18.0 \%$ & $98.6 \%$ & $1.4 \%$ & 100.0 \\
\hline \multicolumn{7}{|c|}{ Household wealth index } \\
\hline Poorest & -1.425 & 0.064 & 0.588 & -0.773 & 0.499 & $4.9 \%$ \\
\hline Second & -1.340 & 0.120 & -0.605 & -1.825 & 0.226 & $28.6 \%$ \\
\hline Middle & -1.302 & 0.176 & -0.245 & -1.371 & -0.038 & $25.2 \%$ \\
\hline Fourth & -1.337 & 0.240 & 0.109 & -0.988 & 0.323 & $11.9 \%$ \\
\hline Richest & -1.270 & 0.286 & 0.185 & -0.799 & -0.845 & $29.4 \%$ \\
\hline Overall & $119.4 \%$ & $-15.8 \%$ & $-0.6 \%$ & $103.0 \%$ & $-3 \%$ & 100.0 \\
\hline
\end{tabular}

Source: 2001DRC-MICS; 2007 DRC-DHS.

DHS, Demographic and Health Surveys; DRC, Democratic Republic of Congo; MICS, multiple indicators cluster survey.

In general, decomposition results indicate that changes in actual diarrhoea prevalence and/or health behaviour are the principal source of decline in diarrhoea prevalence between 2001 and 2007 regardless of the exposure variable (table 3 , column $\mathrm{B}$ ). The analysis of behavioural effect (table 3, columns B1-B3) suggests that the observed decline in diarrhoea prevalence is global (not specific to some socioeconomic characteristics). In other words, the observed changes are due to the general improvement in health behaviour in the DRC. The differentiation effect, the error terms and the composition effect are negligible.

Table 3 (column C) shows also the contribution of each socioeconomic category in the overall decrease of diarrhoea prevalence in the DRC between 2001 and 2007. Depending on the independent variable, decline in diarrhoea prevalence in the following groups have contributed more to the observed changes: Children whose mothers did not attend school (43\%), among children who live in household with toilet but without access to clean water (43\%) and among children living in the richest households $(29 \%)$ and children living in the poorer households $(29 \%)$ have contributed more to the diarrhoea decrease in the DRC between 2001 and 2007. In contrast, small contributions to the overall changes in diarrhoea prevalence are observed from children living in household with 'water alone without toilet' $(10 \%)$ and from children who stay in poorest households $(5 \%)$.

Fixed effects of trends in proportion of child's age, province of residence and household's living condition on trends in prevalence of diarrhoea in DRC

Table 4 displays results from fixed effects models. Overall there are no significant changes in diarrhoea prevalence associated with a variation of the population structure by maternal education, household access to clean water and sanitation as well as by household wealth index.

Table 4 Fixed effect of changes in proportion of children by selected characteristics on changes in diarrhoea prevalence in DRC

\begin{tabular}{|c|c|c|c|c|c|}
\hline & $\boldsymbol{\beta}$ & Constant & $\Sigma \_\mathbf{u}$ & $\Sigma \_$e & $\rho$ \\
\hline Change in proportion of children per maternal education & -0.1052 & 15.626 & 1.478 & 5.203 & 0.070 \\
\hline $\begin{array}{l}\text { Change in proportion of children per living condition (access to clean water and } \\
\text { sanitation) }\end{array}$ & -0.008 & 20.446 & 1.573 & 4.699 & 0.101 \\
\hline Change in proportion of children per household wealth index & -0.1546 & 22.363 & 1.691 & 4.922 & 0.106 \\
\hline
\end{tabular}

\section{Source: 2001DRC-MICS; 2007 DRC-DHS}

${ }^{\star * * *} p<0.01 ;{ }^{* *} p<0.05 ;{ }^{*} p<0.1$.

DHS, Demographic and Health Surveys; DRC, Democratic Republic of Congo; MICS, multiple indicators cluster survey. 
However, differences across years explain $7 \%$ of the variance in the distribution by maternal education, and about $10 \%$ if one considers under-five children's distribution by access to water and toilet and household wealth index, respectively.

\section{DISCUSSION AND CONCLUSION}

This study had a threefold objective. The first was to describe diarrhoea prevalence trends in the DRC, the second was to identify sources of observed changes in diarrhoea prevalence and the third was to assess the contribution of different categories to the observed changes. Exposure variables included maternal education, access to clean water and improved sanitation, and household wealth index. The study used data from the DRC 2001 MICS and 2007 DHS surveys.

Findings from the three complementary statistical methods (trend analysis, decomposition analysis and fixed effect regression models) are consistent. The significant decrease in diarrhoea prevalence observed in the DRC between 2001 and 2007 is regardless of socioeconomic characteristic and the results from trend analysis corroborate the absence of a composition effect revealed by the decomposition as well as no significant changes in diarrhoea prevalence associated with variation of the population structure (results from the fixed effect regression models). Likewise, these results support the decrease in under-five mortality observed in the country since 2001: 213/1000 live births in $2001^{8}$ and $158 / 1000$ live births in $2010 .^{10}$

Furthermore, children of mothers who never attended school, those living in households with toilet alone (without water) and children living in the poorer (second quintile) households as well as those living in the richest households have contributed more than other children to the observed decline in diarrhoea prevalence.

However, the decrease in diarrhoea prevalence in the DRC as well as the decline in child mortality contrast with the generalised humanitarian crisis, deterioration in environmental conditions and population poverty observed in the country in the same study period. The country is among the lowest-ranked nations in the 2011 Global Peace Index (148th of 153 countries). ${ }^{27}$ Since 1996, the DRC has been hit by conflict, which has devastated and destabilised the country. People continue to live in crisis conditions in many parts of the country. The eastern provinces (Orientale, Katanga, Maniema, Nord Kivu and Sud Kivu) are afflicted by violence.

Moreover, the DRC's 2010 Human Development Index (HDI) is estimated at 0.239 , which gives the country a rank of 168 of 169 countries with comparable data despite numerous natural resources. ${ }^{28}$ Overall, the majority of people do not have access to clean drinking water $(54 \%)$ and improved sanitation $(77 \%) .{ }^{13}$ With reference to data used in this study, the proportion of children living in households with access to clean water and improved sanitation diminished from $40 \%$ in 2001 to $28 \%$ in 2007.

Two hypotheses could explain the observed discrepancies between the living conditions and changes in diarrhoea prevalence in the DRC. First, there may be some real improvement in health behaviour, particularly the use of boiled drinking water and adequate washing of hands after contact with adult and child stools. However, we cannot test such hypothesis because of lack of data.

Second, there may be some issues with data quality. In conflict situations, it might be very difficult to collect reliable data. For instance, during the 2001 MICS, in the Eastern part, often interviewers had to stop their work and resume after several days. Rebels arrested a fieldworker for more than 6 weeks (MICS2) (8). Furthermore, diarrhoea prevalence is based on selfreporting. Mothers or caregivers can mis-declare diarrhoea prevalence according to her understanding of diarrhoea definition in the local language. Also, duration of data collection varies considerably by province ( 1 month in Kinshasa and about 2 months in Nord-Kivu and Katanga for the 2001 MICS). In addition, the distribution of children by some socioeconomic characteristics varies across survey. This is probably due to the use of an old national sampling frame from the 1984 Census. However, the methods used (decomposition and fixed effect regression models) control for variation in proportion during analyses.

In conclusion, childhood diarrhoea remains a public health problem in the DRC despite the observed decline. It is noteworthy that the overall significant decrease in diarrhoea prevalence in the DRC is in contrast to the poor living conditions observed in the same period. Our study suggests further studies at the district or province levels to validate findings from national household surveys such as DHS and MICS considering the conflict context of the country when these data were collected and the continuing degradation of the country's socioeconomic and transport infrastructure and security. We hope that the next census in preparation will provide a more comprehensive sampling frame. However, improvement in access to clean water and improved sanitation will contribute to accelerate reduction of diarrhoea prevalence as well as reduction of child mortality.

\section{Author affiliations}

${ }^{1}$ Department of Population and Development studies, University of Kinshasa, Democratic Republic of Congo

${ }^{2}$ CEPS/INSTEAD, University of Luxembourg, Luxembourg

${ }^{3}$ Division of Health Sciences, Populations, Evidence and Technologies Group, Warwick Medical School, University of Warwick, Coventry, UK

${ }^{4}$ Malaria Public Health and Epidemiology Group, Centre for Geographic Medicine, KEMRI-University of Oxford-Wellcome Trust Collaborative Programme, Nairobi, Kenya

Acknowledgements The authors thank Macro international and UNICEF for providing free the 2007 DHS data-sets for the DR Congo and MICS 1-2.

Contributors JBOE participated in conception and design, literature review, data analysis and interpretation, drafting the article, critical revisions for important intellectual content and approval of final article for submission. 
KNB participated in conception and design, interpretation of results, critical revisions for important intellectual content and approval of final article for submission.

Funding This research was supported by the British Council under the DeIPHE (Development Partnership in Higher Education) scheme (Grant No 788).

Competing interests None.

Patient consent Obtained.

Ethics approval Ministry of Plan, DRC.

Provenance and peer review Not commissioned; externally peer reviewed.

Data sharing statement The data can be found at this website www. measuredhs.com

\section{REFERENCES}

1. Black RE, Morris SS, Bryce J. Where and why are 10 million children dying every year? Lancet 2003;361:2-10.

2. UNICEF. The State of the World's Children 2008. New York: UNICEF, 2008

3. UNICEF \& WHO. Diarrhoea: why children are still dying and what can be done. New York: UNICEF \& WHO, 2009.

4. Daniels DL, Cousens SN, Makoae LN, et al. A case-control study of the impact of improved sanitation on diarrhea morbidity in Lesotho. Bull World Health Organ 1990;68:455-63.

5. MacDougall J, McGahey C. Three community-based environmental sanitation and hygiene projects conducted in the Democratic Republic of Congo. New York: USAID, 2003.

6. http://www easterncongo org/mnch(20 Sep, 2012).

7. http://www.who.int/gho/child_health/en/index.html (12 Oct, 2012).

8. Congo RD, UNICEF \& USAID. Enquête nationale sur la situation des enfants et des femmes MICS2/2001. Rapport d'analyse. Kinshasa: République Démocratique du Congo, 2002.

9. République Démocratique du Congo. Enquête Démographique et de santé, Rapport final. Calverton: Macro International Inc, 2008.

10. Institut National de la Statistique et Fonds des Nations Unies pour l'Enfance. Enquête par Grappes a Indicateurs Multiples en République Démocratique du Congo (MICS-RDC 2010), Rapport final. Kinshasa: INS and UNICEF, 2011.

11. République du Zaïre. Enquête nationale sur la situation des enfants et des femmes au Zaïre en 1995. Rapport final. Kinshasa: UNICEF \& Ministère du Plan, 1996
12. Kandala N-b, Emina JB, Nzita Pd, et al. Diarrhoea, accute respiratory infection, and fever among children in the Democratic Republic of Congo. Soc Sci Med 2009:1728-36.

13. WHO \& UNICEF. Progress on sanitation and drinking water. 2010 Update. New York, Geneva: WHO-UNICEF, 2010

14. Curtis V, Cairncross S, Yonli R. Domestic hygiene and diarrhoea-pinpointing the problem. Trop Med Int Health 2000;5:22-32.

15. Mosley WH, Chen LC. Child survival strategies for research. Popul Dev Rev 1984;10:25-45.

16. Esrey SA, Habicht JP. Epidemiological evidence for health benefits from improved water and sanitation in developing countries. Epidemiol Rev 1986;8:117-28.

17. Esrey SA, Potash JB, Roberts L, et al. Effects of improved water supply and sanitation on ascariasis, diarrhoea, dracunculiasis, hookworm infection, schistosomiasis, and trachoma. Bull World Health Organ 1991;69:609-21.

18. Fewtrell L, Kaufmann RB, Kay D, et al. Water, sanitation, and hygiene interventions to reduce diarrhoea in less developed countries: a systematic review and meta-analysis. Lancet Infect Dis 2005;5:42-52

19. http://www.wssinfo.org/definitions-methods/watsan-categories (18 Oct 2012)

20. Huuhtanen S, Laukkanen A. A guide to sanitation and hygiene for those working in developing countries. Tampere: University of Applied Sciences Publications, 2006

21. http://www.measuredhs.com(accessed 20 June 2012).

22. http://www.childinfo.org (accessed 20 June 2012).

23. Filmer D, Pritchett LH. Estimating wealth effects without expenditure data-or tears: an application to educational enrollments in states of India. Demography 2001;38:115-32.

24. http://www.ats.ucla.edu/stat/stata/faq/test_trend.htm (accessed 20 June 2012)

25. Eloundou-Enyengue P, Giroux S. Comprendre le changement social. Apport des méthodes de décomposition, support technique, panel UIESP sur le renforcement de la formation démographique en Afrique francophone. Yaoundé: UIESP, 2010.

26. Romo V. Decomposition analysis in demography. PhD dissertation. Groningen, the Netherlands: Rijksuniversiteit Groningen, 2003.

27. Institute for Economics and Peace. The 2011 Global Peace Index Methodology, results and findings. Sydney: Institute for Economics and Peace, 2011.

28. UNDP. Human Development Report 2010. The Real Wealth of Nations: pathways to human development. New York: UNDP, 2010. 